\title{
QUANTIFICAÇÃO DA INTERMITÊNCIA NA CAMADA LIMITE ESTÁVEL EM UM SÍTIO EXPERIMENTAL NA FLORESTA AMAZÔNICA
}

\author{
Daniel M. dos Santos ${ }^{1}$, Pablo Oiveira ${ }^{1}$, Antônio A. Manzi ${ }^{2}$, Giuliano Demarco ${ }^{1}$, Otávio C. \\ Acevedo $^{1}$ \\ ${ }^{1}$ Universidade Federal de Santa Maria - UFSM \\ ${ }^{2}$ Instituto Nacional de Pesquisa da Amazônia - INPA \\ danielmichelon@gmail.com
}

\section{RESUMO}

O propósito do presente trabalho é utilizar um método de determinação de intermitência e quantificar como esta afeta as séries de temperatura e $\mathrm{CO}_{2}$. Tais análises são feitas para um sítio específico na região Amazônica.

\begin{abstract}
The purpose this work is to use a method of determination of intermittency and quantify how affects the series of temperature and $\mathrm{CO} 2$. Such analyzes are made for a specific site in the Amazon region.
\end{abstract}

\section{INTRODUÇÃO}

Nos últimos anos, estabeleceram-se uma enorme quantidade de estudos observacionais visando à determinação de fluxos de escalares entre a superfície e a atmosfera. Mesmo com o sucesso da técnica da covariância de vórtices, sérias dificuldades associadas a essa metodologia ainda existem (Aubinet, 2008).

As dificuldades estão associadas ao período noturno, quando a intensidade da turbulência é reduzida e essa, pode ter ainda um caráter intermitente (Aubinet, 2008). As consequências da intermitência para o sucesso da técnica da covariância de vórtices foi recentemente reportada por Oliveira et al. (2013), sendo que os mesmos mostram que o ar acumulado localmente na 
copa da vegetação é transferido simultaneamente para cima e para baixo em eventos intermitentes, e que os fluxos de $\mathrm{CO}_{2}$ dependem não somente da intensidade turbulenta, mas como a turbulência evolui em termos da sucessão de eventos calmos e turbulentos.

\section{MATERIAIS E MÉTODOS}

O sítio experimental está localizado na Reserva de Desenvolvimento Sustentável Uatumã AM e pertence ao LBA (Large-Scale Biosphere-Atmosphere Experiment in Amazon). O projeto ATTO (Amazonian Tall Tower Observatory) possui uma torre de $80 \mathrm{~m}$ de altura (S $02^{\circ} 08^{\prime} 38.8^{\text {“ }} \mathrm{O} 58^{\circ} 59^{\prime}$ 59.5), onde estudos de monitoramento da floresta estão sendo desenvolvidos. Dois anemômetros sônicos tridimensionais Campbell CSAT 3D juntamente com medidas de concentração de $\mathrm{CO}_{2}$ e vapor d'água (analisador de gás infravermelho de caminho aberto LI-COR LI-7550) foram instalados em dois níveis (23 e $42 \mathrm{~m}$ ). Um terceiro conjunto composto por um anemômetro sônico e um analisador de gás está instalado no topo da torre $(80 \mathrm{~m})$. Dessa forma se obtiveram perfis verticais de medidas no local $(10 \mathrm{~Hz})$.

\section{RESULTADOS E DISCUSSÃO}

Acevedo et al. (2006) reportou que os valores do fator de intermitência (FI) devem possuir valores próximos a zero para uma noite ser considerada intermitente. Para a noite, iniciada no dia juliano 63 (DJ63), determinou-se os $\mathrm{FI}_{\mathrm{s}}$ para a velocidade de fricção $\left(\mathrm{FI}_{u^{*}}\right)$, fluxo de $\mathrm{CO}_{2}\left(\mathrm{FI}_{\mathrm{CO} 2}\right)$ e fluxo de calor sensível $\left(\mathrm{FI}_{\mathrm{H}}\right)$. Os fatores de intermitência calculados foram $\mathrm{FI}_{\mathrm{u}^{*}}$ $=0,22, \mathrm{FI}_{\mathrm{CO} 2}=0,12 \mathrm{FI}_{\mathrm{H}}=0,19$ (Figura 1), estando todos de acordo com os valores obtidos por Acevedo et al. (2006), indicando assim que a noite DJ63 é considerada intermitente.

A Figura 2 mostra a evolução temporal de $w$, temperatura e concentração de dióxido de carbono para o nível de 42m (logo acima do dossel). No primeiro painel, observa-se que $w$ apresenta 3 eventos intermitentes no período de 0030 HL a 0415 HL. 


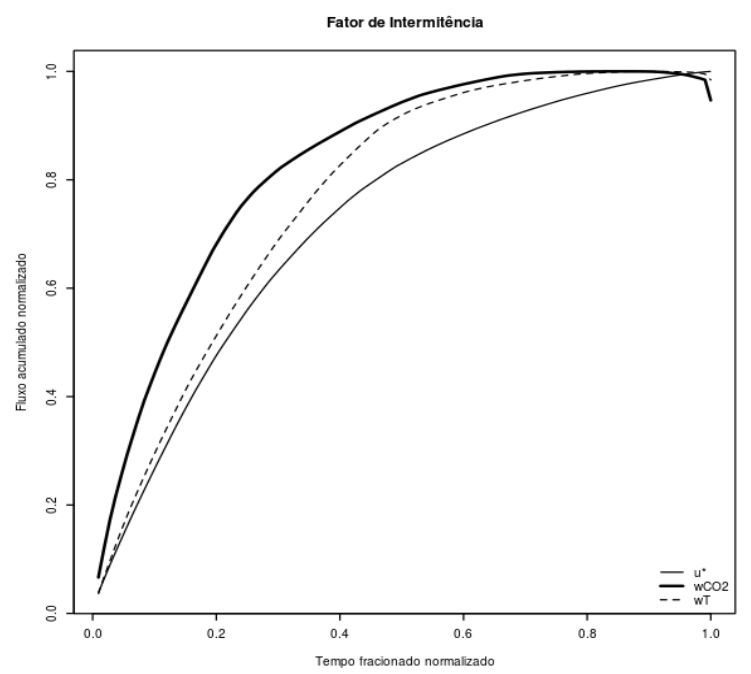

Figura 1 - A fração de tempo requerida para o fluxo total acumulado alcançar 50\%, apresentou valores próximos a zero para os fatores de intermitência de $\mathrm{u}^{*}$, fluxo de $\mathrm{CO}_{2} \mathrm{e}$ fluxo de calor sensível para a noite DJ63.

O primeiro evento ocorre por volta das $0030 \mathrm{HL}$, refletindo imediatamente nas medidas de temperatura e na concentração de $\mathrm{CO}_{2}$. Com o aumento de $w$, percebe-se uma perturbação negativa na temperatura, que decai aproximadamente $2{ }^{\circ} \mathrm{C}$ e começa a apresentar flutuações maiores do que no período de calmaria, fruto da mistura gerada por esse evento (Figura 2, painel central). Já a concentração de $\mathrm{CO}_{2}$ responde de forma contrária à temperatura, sofrendo um acréscimo de aproximadamente $1,5 \mathrm{mmol} . \mathrm{m}^{-3}$ a partir da ocorrência do evento intermitente e da mesma forma aumentando suas flutuações (Figura 2, painel inferior).

Ainda, podemos perceber qualitativamente que as $0320 \mathrm{HL}$ quando o segundo evento intermitente cessa, ocorre um resfriamento abrupto no nível observado assim como um acumulo de $\mathrm{CO}_{2}$. $\mathrm{O}$ evento iniciado as $0410 \mathrm{HL}$ reflete com maior clareza no campo de $\mathrm{CO}_{2}$, pois há um aumento na concentração do gás, o que nos sugere transporte de $\mathrm{CO}_{2}$ de níveis inferiores (provavelmente dentro do dossel) até esse nível. 

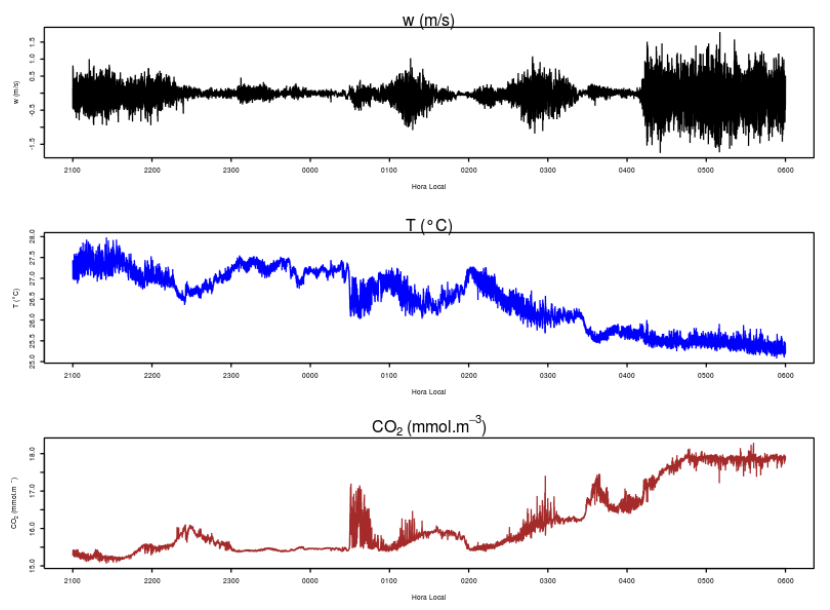

Figura 2 - Vento vertical (w), temperatura e $\mathrm{CO}_{2}$ observados no nível de $42 \mathrm{~m}$, para a noite DJ63, reconhecida como intermitente pelo cálculo do fator de intermitência.

\section{CONCLUSÃO}

A análise prévia foi capaz de mostrar comportamentos típicos de noites com ocorrência de eventos intermitentes, eventos esses que são de grande importância nos cálculos dos fluxos noturnos e são muitas vezes negligenciados.

\section{REFERÊNCIAS}

ACEVEDO, O. C. et al., Intermittency and the exchange of scalars in the nocturnal surface layer. Boundary-Layer Meteorology, vol. 119, p. 41-55, 2006.

AUBINET, M. Eddy covariance $\mathrm{CO}_{2}$ flux measurements in nocturnal conditions: an analysis of the problem. Ecological Applications, v. 18, n. 6, p. 1368-1378, 2008.

OLIVEIRA, P. E. S. et al., Nocturnal Intemittent coupling between the interior of a pine forest and air above it. Boundary-Layer Meteorology, vol. 146, p. 45 - 64, 2013. 